"Mircea cel Batran" Naval Academy Scientific Bulletin, Volume XIX - 2016 - Issue 1

Published by "Mircea cel Batran" Naval Academy Press, Constanta, Romania // The journal is indexed in:

PROQUEST / DOAJ / DRJI / JOURNAL INDEX / I2OR / SCIENCE LIBRARY INDEX / Google Scholar / Crossref /

Academic Keys / ROAD Open Access / OAJI / Academic Resources / Scientific Indexing Services / SCIPIO

\title{
CONSIDERATIONS ON PARTICULAR ASPECTS OF ENGINEERING LANGUAGE
}

\author{
Anca SIRBU ${ }^{1}$ \\ Camelia ALIBEC ${ }^{2}$ \\ ${ }^{1}$ Senior lecturer PhD Department of Fundamental Sciences and Humanities, Constanta Maritime University, \\ 104 Mircea cel Batran Street, Constanta, e-mail: ancasirbu@yahoo.com \\ ${ }^{2}$ Senior lecturer, PhD, Department of Naval and Port Engineering and Management, "Mircea cel Batran" \\ Naval Academy, 1 Fulgerului Street, Constanta, e-mail: cami alibec@yahoo.com
}

\begin{abstract}
Beside the usual communication tools of engineering professionals, i.e. formulae, charts, drawings and the like, language is by far the greatest (sic!) means of conveying professional messages and ideas. Projects, memos and contracts depend not only on their contents as to the reactions and further development they trigger, but also on the linguistic manner in which they are brought forward. Clear and unequivocal phrasing and language are of utmost importance in contracts where any misunderstanding may lead to costly consequences and even more so in building specifications, operating and repair instructions! Engineers are usually less interested in linguistic issues. Nevertheless, they are the exponents of the paradox that they express themselves more clearly and accurately than humanities professionals. The engineering jargon is not made up entirely of symbols, formulae and equations. In order to reach the public sphere, one has to use everyday terms and concepts. Engineering terminology is characterized by specialized terms, certain forms of sentence structures and accuracy of expression. Texts are well structured and have a mainly descriptive nature. From the way texts are conceived and from terms and phrases used in texts at a particular time, one can draw conclusions about the prevailing conditions of the time and about the state of technology at that moment. Consequently, language is in every respect an eclectic phenomenon.
\end{abstract}

Key words: language, engineering terminology, specialized vocabulary, communication

Beside the usual communication tools of engineering professionals, i.e. formulae, charts and graphs, drawings and drafts and the like, language is by far the greatest (sic!) means of conveying professional messages, concepts and ideas. Projects, protocols, memos, minutes and contracts depend not only on their contents as to the reactions and further development they trigger, but also, to a great extent, on the linguistic manner in which they are brought forward. Funding for the most brilliant project may be compromised if the competent decision-making body fails to understand what is at stake. Likewise, clear and unequivocal phrasing and language are of utmost importance in contracts where any misunderstanding may lead to costly consequences and even more so in building specifications, operating and repair instructions! Engineers are usually less interested in linguistic issues. They belong to the occupational groups with less naturally gifted persons in terms of language and communication. It is only normal so, as talent is what spurs most of us to choose a career. People who enjoy speaking and writing, explaining, debating are, of course, more likely to study foreign languages, journalism or philosophy than engineering. As an engineer, you want to plan, to measure, to analyse, to operate, to repair, to develop and certainly not to "chitchat". Nevertheless, engineers are the exponents of the

DOI: 10.21279/1454-864X-16-I1-085

(c) 2015. This work is licensed under the Creative Commons Attribution-Noncommercial-Share Alike 4.0 License. paradox that they express themselves more clearly and accurately than sociologists, politicians and other humanities professionals.

The engineering jargon is not made up entirely of symbols, formulae and equations. Language is a significant element in the communication among specialists on the one hand and between specialists and laymen on the other hand. The semantic question on what particular terms to choose in order to express your ideas comprehensibly is posed in the field of exact sciences as well. In order to reach the public sphere, one has to use everyday terms and concepts. In everyday life energy is rather similar to vitality, verve or zeal, depending on the context, while in physics for instance "energy is a property of objects which can be transferred to other objects or converted into different forms. The "ability of a system to perform work" is a common description, but it is difficult to give one single comprehensive definition of energy because of its many forms. For instance, in SI units, energy is measured in joules, and one joule is defined "mechanically", being the energy transferred to an object by the mechanical work of moving it a distance of 1 metre against a force of 1 newton. However, there are many other definitions of energy, depending on the context, such as thermal energy, radiant energy, electromagnetic, 


\section{"Mircea cel Batran" Naval Academy Scientific Bulletin, Volume XIX - 2016 - Issue 1 Published by "Mircea cel Batran" Naval Academy Press, Constanta, Romania /I The journal is indexed in: PROQUEST / DOAJ / DRJI / JOURNAL INDEX / I2OR / SCIENCE LIBRARY INDEX / Google Scholar / Crossref / Academic Keys / ROAD Open Access / OAJI / Academic Resources / Scientific Indexing Services / SCIPIO}

nuclear, etc., where definitions are derived that are the most convenient." [1]

Engineering terminology is characterized by specialized terms, certain forms of sentence structures and accuracy of expression. Texts are well structured and have a mainly descriptive nature. Language is not only a tool, it also mirrors contemporary history. From the way texts are conceived and from terms and phrases used in texts at a particular time, one can draw conclusions about the prevailing conditions of the time and about the state of technology at that moment. Consequently, language is in every respect an eclectic phenomenon.

Alongside the development of crafts and trades and then, in the course of history, the advent of new technologies, mankind faced new "language needs": people needed technical terms in order to accurately and unequivocally name the newly invented objects and concepts of a subject area as well as their related properties and activities. But for all that, in addition to the new technical terms, idioms emerged which, due to their special character, can prove to be not only incomprehensible but also misleading for a layman. Hence, a specialized language is more than the mere sum of its pertaining technical terms. Jargons are of course not entirely detached from the common language - it is embedded in the language just as bricks in a wall, they are interwoven. The one originates in the other and usually the same rules and building laws apply for both. The differences lie in the specialized words and phrases and in the specific grammatical and syntactic structures.

An important aspect of technical texts is that the wording should remain the same throughout the whole text, so as not to confuse the reader. Everyone knows how bothering it is to read instructions or a repair manual where the same process or the same machine part bears different names in different paragraphs. This is mostly the case of manuals of electronic devices. But in an engineering text it would be entirely wrong to keep changing the name a machine part just to make the text more attractive so as to avoid recurrence. For example, the terms rod, push rod and drive rod are not the same thing. How would the reader know what the builder really means?

The need for technical terms and phrases has been increasing with the development of each particular technical field. To illustrate this extent, let us take into account the fact that the active vocabulary of "the educated" amounts to about 10,000 words while the total vocabulary of the standard language is 300,000 to 400,000 words. A good dictionary displays around 100,000 entries, a size that technical dictionaries easily attain, too. In engineering, where a marine engine for instance, which is quite large, consists of more than 1,000 identified components among which there are functional groups which in turn are made up of numerous individual parts, it appears we actually deal with up to 7,000 to 8,000 parts. [2] Whereof, most of them are "recurrent parts", i.e. they occur several times, so the listing of a marine engine structure may only come down to ca. 800 words. Further on, specialists need to find names for the whole engine environment, its functions and features and for the engine-specific abstract terms. Through the introduction of electronics in engineering, the engine terminology has been extended de facto by gaining the domain of electronics as well. In other words, the number of technical terms is not even closely to estimate. No wonder they say that technology is the greatest "contractee of the language" and engineers are referred to as "originator of language".

Technical terms are the scaffolding of jargon and there is a smooth transition from the colloquial term on through the more general term to the specialized term. Terms have to be made linguistically manageable, by means of designation. The connection between a concept and its designation is achieved through a definition. The designation, therefore, should refer back to the definition and is expected to be as clear and unambiguous as possible. The definition should explain the relevant characteristics of the term and, at the same time, express the features of the notion or the concept as well. "Once a standardised or non-standardised term is associated to a concept in an important area of usage, it can survive as name of this concept, even if the concept evolves or if the conceptual system changes. There are many examples of stable terms in the history of science and technology which designate concepts which have undergone substantial changes. In this case it is the definitions that carry the burden of up-dating. Every coherent corpus of definition constitutes a terminological object as son as it refers to a group of concepts or a specified practical social domain." [3] In engineering and technology, the following concepts are usually denominated:

- material objects: crankcase, pistons, cylinders, valves;

- concepts: performance, capacity;

- features: top-heavy, power to weight ratio;

- behaviour: fuel consumption, fumes emission;

- processes: overheating, flooding;

- activities: repair, lubricate, start, stop.

In terms of structure, most terms in engineering are compound words, mainly made up of a basic 


\begin{abstract}
"Mircea cel Batran" Naval Academy Scientific Bulletin, Volume XIX - 2016 - Issue 1
Published by "Mircea cel Batran" Naval Academy Press, Constanta, Romania /I The journal is indexed in: PROQUEST / DOAJ / DRJI / JOURNAL INDEX / I2OR / SCIENCE LIBRARY INDEX / Google Scholar / Crossref /

Academic Keys / ROAD Open Access / OAJI / Academic Resources / Scientific Indexing Services / SCIPIO
\end{abstract}

component (a noun or a noun phrase) and a determiner (nouns, adjectives, verbs or prepositions). As for the notions they designate and the manner they turn into compounds, the following examples apply:

- the material from which the machine/equipment or machine part is made: lead-bronze bearing, cast iron casing, rubber gasket;

- the shape of the tool or equipment or machine part: cross-head screwdriver, $V$-engine, square spanner;

- the place where the machine is installed or its destination: rail engine, marine engine;

- location of the machine part: cylinder head top, inner spring, outer spring;

- the time or duration of the machine running or of the technological process: breaker contact, longtime radiation, short-time operation;

- the system or the machine that the machine part belongs to: main engine cylinder, piston rod stuffing box;

- function of the machine part denominated by the basic component in the compound phrase: injection pump, fuel oil tank, exhaust valve, inlet manifold;

- the type of force carrier that causes the engineering process: internal combustion engine, turbocharger, torque indicator;

- indication of the inventor: Diesel engine, Otto cycle, Roots-type supercharger;

- indication of the producer: Allen wrench, Phillips screwdriver, Bristol wrench;

- indication of the person operating the machine: (marine) engineer, machinist, machine operator;

- the property or importance of a machine part: main engine, auxiliary engine, ancillary unit;

- tools or machine parts named after body parts: flat nose pliers, long nose pliers, jaw spanner, hand wheel, crosshead;

- machine parts or tools taking alphabet letters in their names: A-frame, C-wrench, O-ring, $V$ engine;

- tools or machine parts named according to their origin: Swedish pliers, Swiss army knife;

Metaphors through the visual comparison they trigger play a major role in the engineering language. There are several explanations to that: one of them is, of course, the fact that an engine is made up of numerous parts, all of which needed to be named at a certain moment, hence the "language demands"; secondly, going back to the origins of the internal combustion engine, one has to bear in mind the fact that the main parts of this engine were taken over from the older steam engine along with the names of the components. These names were once formed on the spot and they consolidated their position in time. A joy of the pictorial was clearly visible in that century and the use of metaphors was due to the structure of human reckoning that made analogies caused by similarities to the surrounding world. For example, a cylinder head represents the head (i.e. the upper part) of the engine. Analogies were also made to certain processes, e.g. suction engine. Concepts need names and these should be precise and clear so as to make complex connections as comprehensible as possible. A metaphor will set the focus of a process or an operation verbally within a name or a term that in turn will serve as a code used to decipher a complex notion. Humans think in a human manner, therefore they see themselves as the point of origin of their conceptual system of coordinates. Hence, the plurality of human body and human life related metaphors, i.e. human activities, features and behaviour that serve as templates for terms in engineering, followed closely by items of clothing, dwelling, fauna, flora etc.:

- human body: cylinder head, eyebolt, flat nose pliers, crank cheek, toothed wheel, bearing neck, shoulder screw, thumb brake, gripper finger, rocker arm, nipple, water gauge body, handwheel, knee, foot valve;

- dwelling: valve housing, combustion chamber, bedplate, threshold, plug seat, ramp generator, mast step, wall powered drill, cushion grip;

- clothing items: tube sleeve, engine jacket, collar, brake shoe;

- fauna: crow bar, butterfly valve, fuel cock, bench dog, caterpillar track, driving worm;

- flora: apple seed file, flow bean, pear-head rail, nut tap, peanut tube;

- musical instruments: trumpet gland, whistle tip exhaust pipe, boiler drum;

- colours: black flange, white iron, red hardness, blue tempering, green bond strength;

- personal and household items: comb cylinder shaft, mirror iron, apron conveyor, fork spanner, basket strainer, pot furnace;

A compilation of engineering terms as the ones mentioned above reveals the subtle and finely woven way in which the patterns of naming engineering items comprise the entire surroundings of mankind. In the evolution of mankind, however, sciences and the terminologies thereof evolve as well. In biology and chemistry, for example, the pertaining jargon, although in constant evolution, still has to maintain "traces of the previous states of knowledge. Scientific terminology therefore must register these changes of relationship between partly old terms and new concepts. [...] The development of engineering is subject to different laws. Each 
"Mircea cel Batran" Naval Academy Scientific Bulletin, Volume XIX - 2016 - Issue 1

Published by "Mircea cel Batran" Naval Academy Press, Constanta, Romania // The journal is indexed in:

PROQUEST / DOAJ / DRJI / JOURNAL INDEX / I2OR / SCIENCE LIBRARY INDEX / Google Scholar / Crossref /

Academic Keys / ROAD Open Access / OAJI / Academic Resources / Scientific Indexing Services / SCIPIO

application of scientific knowledge, each improvement in the process of mechanisms for the realisation of engineering applications is followed by a major change in the world of manufactured objects. Whereas before the nineteenth century it was largely a matter of reducing the denominations in order to standardise the names of a relatively small number of processes and tools, today we witness a constant multiplication of man-made objects resulting from technical developments. [...] The motor car, for example, because of its wide use, has a conservative terminology with respect to technical developments." [4]

But for all that, who establishes terms, on what occasion are new terms created? Technicians, mechanics and engineers have to designate parts, test engineers and scientists have to deal with processes and phenomena, so they give explanations and make suggestions for terms. "Standardisation experts [...] have a quite different task. They can [...] identify concrete features which current terminology reflects poorly or badly. For this reason they tend to propose terms usually by combining available names - or choose among several possible and competing terms.
This applies most frequently to the fields of economics, industry and commerce; the terminologies of institutions and of the exact sciences standardise themselves. In order to regulate them, standardisation requires the most complete information on the terminologies in effective use." [5]

Language is the most important tool of specialist in the field of engineering. Communication needs in specialized fields are suited by jargons, which are characterised by technical terms, special linguistic terms and certain forms of sentence structure. Characteristic are also scarcity and accuracy of expression while the proportion of metaphors in engineering is conspicuously high. Engineering texts must be conceptually well structured and coherent in wording, so that the difficult concepts can be unequivocally understood. These texts are mainly descriptive and the vocabulary is precise and abundant in instructions. The intricate and sophisticated field of engineering requires well trained professionals and an intensive professional communication, which should prevent the occurrence of language barriers.

\section{BIBLIOGRAPHY:}

[1] https://en.wikipedia.org/wiki/Energy

[2] http://www.marineengineering.org.uk/page46.html

[3] Rey, Alain, Essays on Terminology / Alain Rey; translated and edited by Juan C. Sager; introduction by Bruno de Bessé., John Benjamins Publishing Company, Amsterdam. Philadelphia. 1995, p. 109

[4] Rey, Alain, Essays on Terminology / Alain Rey; translated and edited by Juan C. Sager; introduction by Bruno de Bessé., John Benjamins Publishing Company, Amsterdam. Philadelphia. 1995, pp. 103-104

[5] Rey, Alain, Essays on Terminology / Alain Rey; translated and edited by Juan C. Sager; introduction by Bruno de Bessé., John Benjamins Publishing Company, Amsterdam. Philadelphia. 1995, p. 101 